\title{
Outcomes of Nasal Septal Perforation Repair Using Combined Temporoparietal Fascia Graft and Polydioxanone Plate Construct
}

Justin Morse, MD; Jacqueline Harris, BS; Scott Owen, MD; Justin Sowder, MD; Scott Stephan, MD

IMPORTANCE Numerous techniques are used for septal perforation repair, yet success rates remain variable. Few studies have evaluated the effectiveness of interposition grafts of polydioxanone plates combined with a temporoparietal fascia graft for septal perforation repair.

OBJECTIVE To investigate and describe the use of interposition grafts of polydioxanone plates combined with a temporoparietal fascia graft for septal perforation repair and the expansion of this technique to patients with more challenging comorbidities, including granulomatosis with polyangiitis.

DESIGN, SETTING, AND PARTICIPANTS A retrospective medical record review was performed of patients who underwent septal perforation repair using interposition grafts of polydioxanone plates combined with a temporoparietal fascia graft from January 1,2015 , to July 1, 2018, at Vanderbilt University Medical Center and from January 1, 2017, to July 1, 2018, at the University of lowa.

INTERVENTION All patients underwent septal perforation repair with interposition grafts of polydioxanone plates and a temporoparietal fascia graft.

MAIN OUTCOMES AND MEASURES Assessing closure of septal perforation was the primary outcome. Secondary outcomes were resolution of presenting symptoms of septal perforation, area of perforation, length of postoperative stent and silastic sheeting placement, postoperative complications and resolution, and duration of follow-up. Preoperative and postoperative Nasal Obstruction Symptom Evaluation (NOSE) scores were assessed.

RESULTS A total of 17 patients ( 12 women and 5 men; mean [SD] age, 45 [15] years) were included. The causes of perforations were iatrogenic (9 [53\%]), rheumatologic (2 [12\%]), and unknown or idiopathic (6 [35\%]). Patients most commonly presented with nasal crusting (12 [71\%]), whistling (9 [53\%]), nasal obstruction (9 [53\%]), and epistaxis (5 [29\%]). Mean (SD) perforation size was $0.99(1.04) \mathrm{cm}^{2}$. Mean (SD) postoperative follow-up was 6.1 (4.1) months. A total of 15 patients ( $88 \%$ ) had complete resolution of presenting symptoms at last follow-up. All perforations were closed with overlying mucosa at the most recent follow-up examination. Nine of 17 patients completed both preoperative and postoperative NOSE. There was a significant difference between the mean (SD) preoperative and postoperative NOSE scores (62.78 [27.74] vs 17.78 [15.83]; $P=.004)$.

CONCLUSIONS AND RELEVANCE Repair of symptomatic nasal septal perforations using a temporoparietal fascia graft combined with a polydioxanone plate was associated with positive outcomes. Repair of septal perforations caused by rheumatologic disease, including granulomatosis with polyangiitis, can be considered for repair using this technique. Resolution of symptoms appeared to be clinically more meaningful in evaluation of septal perforation repair than rate of perforation closure, and the NOSE scale has the potential to serve as an objective corroboration to patient-reported postoperative outcomes.

LEVEL OF EVIDENCE 4.

JAMA Facial Plast Surg. 2019;21(4):319-326. doi:10.1001/jamafacial.2019.0020

Published online April 11, 2019.
Author Affiliations: Department of Otolaryngology-Head and Neck Surgery, Vanderbilt University School of Medicine, Nashville, Tennessee (Morse, Harris, Sowder, Stephan); Department of Otolaryngology-Head and Neck Surgery, University of lowa Hospitals and Clinics, lowa City (Owen).

Corresponding Author: Justin Morse, MD, Department of Otolaryngology-Head and Neck Surgery, Vanderbilt University Medical Center, 1215 21st Ave S, Ste 7209, Nashville, TN 37232-8605 (justin.morse@vanderbilt.edu). 
S eptal perforations have numerous causes and are a significant source of morbidity for the patients affected. Symptoms include epistaxis, nasal crusting, whistling, nasal obstruction, and saddle nose deformity, which commonly leads these patients to present to facial plastic surgeons seeking repair. The cause can be trauma, inhalation medications, systemic vasculitis (such as granulomatosis with polyangiitis), or iatrogenic. Numerous techniques have been developed for repair, including the use of local intranasal flaps with closure of the mucoperichondrium, ${ }^{1,2}$ alloplasts, ${ }^{3}$ pericranial flaps, ${ }^{4}$ grafting with acellular human dermal allograft, ${ }^{5}$ and, more recently, interposition grafting using both synthetic ${ }^{6,7}$ and autologous grafting material. ${ }^{8}$ Many of these techniques are technically challenging and may also serve to obstruct or functionally distort the nasal airway. ${ }^{9}$ In addition, success rates of effective closure and resolution of symptoms remain variable, with reported success rates of 30\% to $100 \%$ in small case series..$^{10}$ Of all the techniques reported, interposition grafts of polydioxanone (PDS) plates combined with a temporoparietal fascia (TPF) graft have demonstrated the highest success rates, ranging from $90 \%{ }^{6}$ to $100 \% .{ }^{11}$ This approach does not attempt to close or approximate the mucosal edges across the perforation but instead provides an ideal scaffold of mesenchymal origin to revascularize and promote mucosal regrowth.

Temporoparietal fascia grafts have a proven success rate in the repair of anterior skull base defects ${ }^{12}$ and have been used with success for other reconstructive procedures, including pharyngeal repair ${ }^{13}$ and microtia reconstruction. ${ }^{14}$ Two prior retrospective case series have evaluated the combined use of PDS plates with a TPF graft for nasal septal perforation and have demonstrated excellent effectiveness. ${ }^{6,11}$ Histologic studies evaluating TPF grafts demonstrate a well-organized, layered extracellular matrix of both collagen and elastic fibers of this tissue, likely leading to its successful application as a scaffold for cellular regeneration. ${ }^{15}$

We aim to present the first multi-institutional investigation of this technique, to our knowledge, and corroborate the results of the prior 2 case series. In addition, a subset of the perforations of patients treated in this study were secondary to granulomatosis with polyangiitis, which, to our knowledge, is the first time this technique has been used for these types of patients. Ultimately, this subset is an expansion of the technique to more challenging comorbidities. In addition to reporting the rate of septal perforation closures, we think that symptom resolution constitutes a clinically meaningful outcome measure and therefore report the resolution of presenting symptoms substantiated through preoperative and postoperative Nasal Obstruction Symptom Evaluation (NOSE) scores (where higher scores indicate greater nasal obstruction). ${ }^{16,17}$

\section{Methods}

\section{Study Design}

A retrospective medical record review was performed of all septal perforation repairs using interposition grafts of PDS plates

\section{Key Points}

Question Are symptomatic nasal septal perforations repaired effectively using a temporoparietal fascia graft combined with a polydioxanone plate?

Findings In this multi-institutional cohort study of 17 patients, 15 patients (88\%) had complete resolution of presenting symptoms at the last follow-up appointment, with all perforations noted to be closed with overlying mucosa. A significant difference between the mean preoperative and postoperative Nasal Obstruction Symptom Evaluation scores was demonstrated.

Meaning Repair of symptomatic nasal septal perforations using a temporoparietal fascia graft combined with polydioxanone plate was associated with positive outcomes; repair of septal perforations caused by rheumatologic disease, including granulomatosis with polyangiitis, can be considered for repair using this technique.

combined with a TPF graft from January 1, 2015, to July 1, 2018, at Vanderbilt University Medical Center and from January 1, 2017, to July 1, 2018, at the University of Iowa. This period was chosen to capture all patients who underwent repair with this technique. This study was approved by the institutional review boards of Vanderbilt University Medical Center and the University of Iowa. Patient consent was waived as all data were deidentified.

All patients were included in the study. There were no exclusion criteria. The primary end point was the closure of septal perforation. Secondary outcomes included reported resolution of presenting symptoms of septal perforation, smoking status, cause of perforation, area of perforation, area and size of TPF flap harvested, length of postoperative stent and silastic sheeting placement, length of time between initial visit and surgery, postoperative complications, duration of follow-up, nasal saline use before and after surgery, and preoperative and postoperative NOSE scores. The size of the septal perforation was calculated using in-office measurements, and an area was extrapolated based on the area of an ellipse ([ $\pi \times$ major radius $\times$ minor radius]/4), which best approximates the shape of septal perforations.

\section{Patient Evaluation}

The initial evaluation gathered pertinent clinical information regarding the cause of perforation, chronicity, and the following related symptoms: crusting, nasal pain, epistaxis, obstruction, whistling, and change in external nasal appearance. If the cause was unknown, a standard laboratory rheumatologic workup was completed. An endoscopic evaluation of the perforation and nasal cavity was performed, followed by measurement in 2 dimensions. Attention was given to exposed bone or cartilage at the margins of the perforation, the location of the perforation and its proximity to the caudal septum, and the degree of mucosal inflammation throughout the nasal cavity.

After the initial evaluation, each patient was required to perform a consistent daily nasal hygiene regimen of saline irrigation followed by the use of a topical moisturizer for approximately 3 months. The use of oxymetazoline hydrochloride was stopped. This period of medical therapy served several 


\section{Figure 1. Preoperative and Postoperative Images of Septal Perforation Repair}

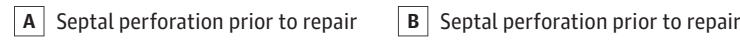

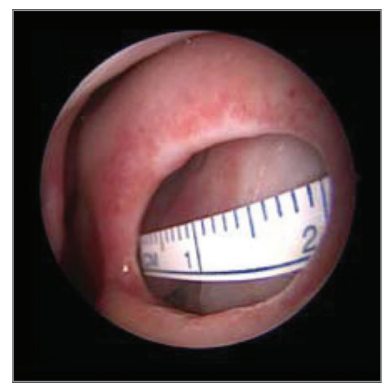

D Left view of septal perforation immediately after repair

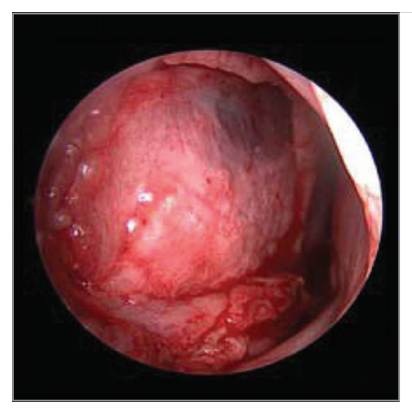

E Remucosalization on the right 10 wk after repair
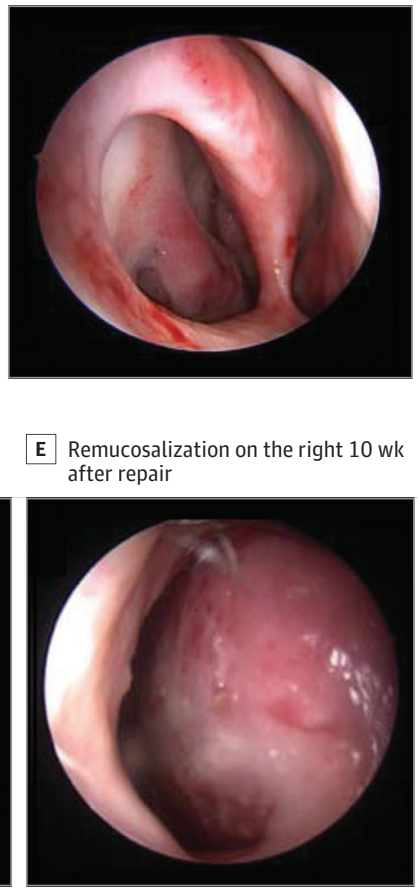

C Right view of septal perforation immediately after repair

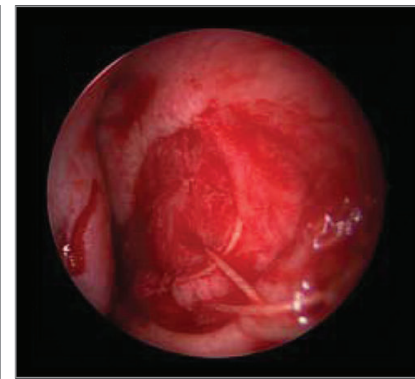

F Remucosalization on the left 10 wk after repair

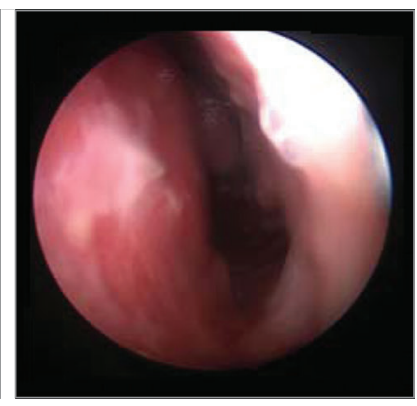

A, Intraoperative, endoscopic view of septal perforation prior to repair showing size of perforation. B, Intraoperative, endoscopic view of septal perforation prior to repair. C, Intraoperative, endoscopic right view of septal perforation immediately after repair with temporoparietal fascia (TPF) graft and polydioxanone plate construct in place. D, Intraoperative, endoscopic left view of septal perforation immediately after repair with TPF graft and polydioxanone plate construct in place. E, Endoscopic visualization 10 weeks after the procedure shows complete remucosalization of perforation on the right with widely patent nasal airway. F, Endoscopic visualization 10 weeks after the procedure shows complete remucosalization of perforation on the left with widely patent nasal airway. purposes. For those who previously had not engaged in routine nasal hygiene care, this regimen might have served to eliminate their symptom profile entirely, obviating the need for perforation repair. For those who remained symptomatic while receiving medical therapy, it allowed for a time interval to evaluate changes in perforation size or mucosal characteristics. In cases in which there was an autoimmune cause, surgical repair was not offered until the patient reached a relative steady state of medical therapy for 6 to 12 months guided by their rheumatologist.

\section{Surgical Technique}

\section{Access to Perforation and Septal Flap Elevation}

Prior to incision, the septal perforation was visualized endonasally and again measured (Figure 1A and B). An external approach to the septum was used. Marginal and transcolumellar inverted V-shaped incisions were made sharply, with care taken to preserve as much blood supply to the anterior septum as possible. Supraperichondrial elevation was performed over the nasal cartilages, and the septum was then approached from above. The upper lateral cartilages were sharply separated from the cartilaginous dorsum. The anterior septal angle was identified, and a submucoperichondrial plane was elevated carefully to keep the septal flaps intact on both sides. If access to the caudal septum was required, the lower lateral cartilages were divided sharply. Dissection continued posteriorly to the bony-cartilaginous junction. The perforation was then entered from above, sharply coupled with sharp entry using a 12-blade scalpel endonasally to ensure that the margins of the flap did not tear. A moderate amount of septal cartilage and bone was resected around the perforation to allow for direct approximation of the TPF with the vascularized septal perichondrium and periosteum. This procedure served to correct any nasal obstruction present, allowed for greater relaxation of the draping septal flaps, and ensured that there was abundant approximation of vascularized septal mesenchymal layers about both sides of the TPF graft.

Harvest of TPF Graft and Fascial Coverage of PDS Plate A horizontal incision was made at the level of the midtemporalis muscle (Figure 2A). Dissection continued through subcutaneous tissue to identify the TPF. Electrocautery dissection was used to elevate the subcutaneous tissue off the TPF widely while avoiding injury to the overlying hair follicles. The loose areolar tissue comprising the TPF was then harvested off the true deep temporal fascia (Figure $2 \mathrm{~B}$ and $\mathrm{C}$ ).

A 0.15-mm PDS plate was covered on both sides under stretch with TPF and tailored to appropriate dimensions. It was then thoroughly sutured to the PDS plate using a mattress technique with an absorbable suture (Figure 2D and E).

\section{Placement of TPF-PDS Plate Construct, Closure,}

and Placement of Splint and Sheet

The construct was placed via external approach to completely fill the space of the perforation (Figure $2 \mathrm{~F}$ ). No attempt was made to close the mucosal defect. The medial crura were reapproximated. Septal flaps were closed using an absorbable mattress suture to obliterate the potential space and lock the PDS-TPF construct in the proper position. The nasal 
Figure 2. Temporoparietal Fascia (TPF) Graft Harvest and Construct Formation

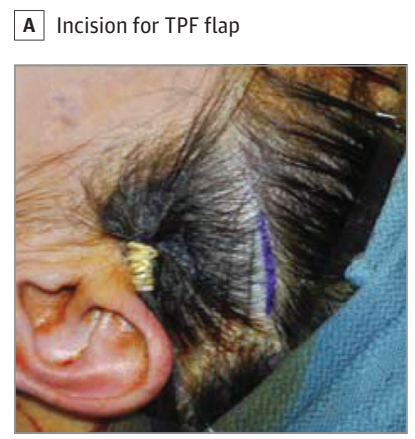

B Harvest of TPF

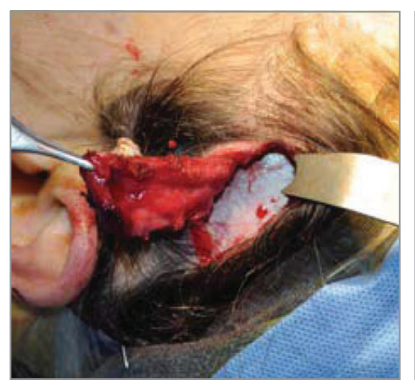

C TPF graft after harvest

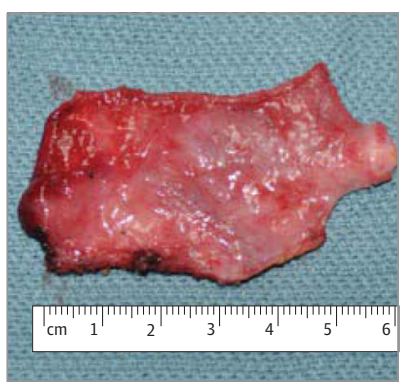

D Graft wrapped around PDS plate E Construct trimm
of perforation
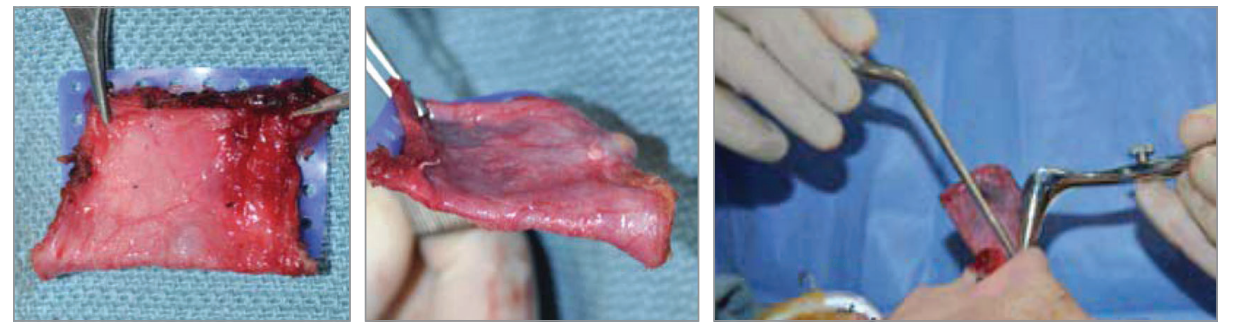

A, Incision for TPF flap. B, Harvest of TPF off of deep temporal fascia. C, Graft after harvest. D, The graft is wrapped around the polydioxanone (PDS) plate. E, The new construct is trimmed to dimensions of the perforation. $F$, The entire construct is placed through an external approach with upper lateral cartilage disarticulated.

skin envelope was redraped, and the transcolumellar and marginal incisions were closed.

With the use of bilateral nasal endoscopy, customized thin silastic sheets $(1.02 \mathrm{~mm}$ ) were placed over the septum to cover the exposed TPF and then secured. This covering served to maintain a near constant level of moisture for the exposed TPF for optimal remucosalization. If inferior turbinate surgery was performed concurrently, Doyle splints were also placed. Endonasal visualization ensured the successful placement of the TPF-PDS construct after closure of the nose (Figure 1C and D). Patients were discharged the same day as the surgery. Doyle splints were removed postoperatively in 7 to 10 days. Silastic sheeting was removed 5 to 6 weeks postoperatively. Remucosalization was assessed endonasally after removal of the silastic sheets and at future postoperative visits (Figure $1 \mathrm{E}$ and F).

\section{Statistical Analysis}

Descriptive statistics were examined for each variable. The Wilcoxon matched-pairs signed rank test was performed when comparing preoperative and postoperative NOSE scores. Only patients with both a preoperative and a postoperative NOSE score were included in NOSE survey analysis. Statistical analyses were performed with Prism 7 software (Graphpad). All $P$ values were from 2 -sided tests, and results were deemed statistically significant at $P<.05$.

\section{Results}

\section{Patient Characteristics}

This case series included 17 patients (12 women and 5 men; mean [SD] age, 45 [15] years). The causes of perforations were iatrogenic from prior septoplasty (9 [53\%]), rheumatologic
(2 [12\%]), and unknown or idiopathic (6 [35\%]) (Table 1). Patients most commonly presented with nasal crusting (12 [71\%]), whistling (9 [53\%]), nasal obstruction (9 [53\%]), and epistaxis (5 [29\%]). The mean (SD) perforation size was 0.99 (1.04) $\mathrm{cm}^{2}$. Two patients (patient 13 and patient 15) had 2 perforations that underwent simultaneous repair. Three patients (18\%) were former smokers. Patient comorbidities included diabetes (1 [6\%]), obstructive sleep apnea (1 [6\%]), and active rheumatologic disease (2 [12\%]). Fourteen patients underwent repair at Vanderbilt University Medical Center, and 3 patients underwent repair at the University of Iowa. Patient characteristics are further detailed in Table 1.

\section{Surgical Outcomes}

All patients underwent an open septoplasty approach for surgical correction of septal perforation. The mean (SD) postoperative follow-up was 6.1 (4.1) months. All septal perforations were closed with overlying mucosa at the most recent follow-up examination. A total of 15 patients (88\%) had complete resolution of presenting symptoms at the last follow-up appointment. No patients have required revision surgery. Of the patients without resolution of symptoms, one (patient 3) has had persistent crusting and nasal obstruction. The other patient (patient 10) has had persistent crusting with mild obstruction. Nine patients (59\%) also completed preoperative and postoperative NOSE surveys. There was a significant difference between mean (SD) preoperative and postoperative NOSE scores (62.78 [27.74]; 95\% CI, 41.46-84.10 vs 17.78 [15.83]; 95\% CI, 5.61-29.95; $P=.004$ ), corroborating patient-reported resolution of subjective symptoms. Postoperative complications included a single temporal scalp seroma in addition to selflimited mild pain, crusting, and epistaxis. Surgical results are further detailed in Table 2. 


\begin{tabular}{|c|c|c|c|c|c|c|c|}
\hline Patient No. & $\begin{array}{l}\text { Age at } \\
\text { Repair, y }\end{array}$ & Sex & Cause of Perforation & $\begin{array}{l}\text { History of } \\
\text { Rheumatologic or } \\
\text { Autoimmune Disease }\end{array}$ & $\begin{array}{l}\text { History of Prior } \\
\text { Septoplasty }\end{array}$ & Perforation Symptoms & $\begin{array}{l}\text { Resolution of } \\
\text { Presenting } \\
\text { Symptoms }\end{array}$ \\
\hline 1 & $40 \mathrm{~s}$ & $\mathrm{~F}$ & $\begin{array}{l}\text { Granulomatosis polyangiitis and } \\
\text { systemic lupus erythematosus }\end{array}$ & Yes & No & $\begin{array}{l}\text { Epistaxis, crusting, and } \\
\text { pain }\end{array}$ & Yes \\
\hline 2 & $60 \mathrm{~s}$ & $\mathrm{~F}$ & Idiopathic & No & No & Crusting and whistling & Yes \\
\hline 3 & $60 \mathrm{~s}$ & M & Idiopathic & No & Yes & Crusting and obstruction & No \\
\hline 4 & $30 \mathrm{~s}$ & M & latrogenic & No & No & $\begin{array}{l}\text { Obstruction and saddle } \\
\text { nose deformity }\end{array}$ & Yes \\
\hline 5 & $60 \mathrm{~s}$ & $\mathrm{~F}$ & Unknown & No & No & $\begin{array}{l}\text { Epistaxis, crusting, and } \\
\text { whistling }\end{array}$ & Yes \\
\hline 6 & $<20$ & $\mathrm{~F}$ & latrogenic & No & Yes & Epistaxis and obstruction & Yes \\
\hline 7 & $40 \mathrm{~s}$ & $\mathrm{~F}$ & latrogenic & No & Yes & Epistaxis & Yes \\
\hline 8 & $60 \mathrm{~s}$ & $\mathrm{~F}$ & Traumatic & No & No & Crusting and obstruction & Yes \\
\hline 9 & $40 \mathrm{~s}$ & $\mathrm{~F}$ & $\begin{array}{l}\text { Idiopathic and systemic lupus } \\
\text { erythematosus }\end{array}$ & Yes & No & Whistling & Yes \\
\hline 10 & $60 \mathrm{~s}$ & $\mathrm{~F}$ & Idiopathic and Graves disease & Yes & No & Crusting and obstruction & No \\
\hline 11 & $40 \mathrm{~s}$ & $\mathrm{~F}$ & Unknown & No & No & Crusting and whistling & Yes \\
\hline 12 & $30 \mathrm{~s}$ & $\mathrm{~F}$ & latrogenic & No & Yes & Crusting and whistling & Yes \\
\hline 13 & $20 \mathrm{~s}$ & M & latrogenic & No & Yes & $\begin{array}{l}\text { Crusting, obstruction, and } \\
\text { whistling }\end{array}$ & Yes \\
\hline 14 & $40 \mathrm{~s}$ & M & latrogenic & No & Yes & $\begin{array}{l}\text { Epistaxis, crusting, and } \\
\text { whistling }\end{array}$ & Yes \\
\hline 15 & $30 \mathrm{~s}$ & M & latrogenic and Crohn disease & Yes & Yes & Obstruction and whistling & Yes \\
\hline 16 & $30 \mathrm{~s}$ & $\mathrm{~F}$ & latrogenic & No & Yes & $\begin{array}{l}\text { Crusting, obstruction, and } \\
\text { whistling }\end{array}$ & Yes \\
\hline 17 & $50 \mathrm{~s}$ & $\mathrm{~F}$ & latrogenic & No & Yes & Crusting and obstruction & Yes \\
\hline
\end{tabular}

\begin{tabular}{|c|c|c|c|c|c|c|c|c|}
\hline \multirow[b]{2}{*}{ Patient No. } & \multirow{2}{*}{$\begin{array}{l}\text { Perforation } \\
\text { Size, } \mathrm{cm}\end{array}$} & \multirow{2}{*}{$\begin{array}{l}\text { TPF Flap } \\
\text { Size, cm }\end{array}$} & \multirow{2}{*}{$\begin{array}{l}\text { Perioperative } \\
\text { Complications }\end{array}$} & \multirow{2}{*}{$\begin{array}{l}\text { Resolution of } \\
\text { Perioperative } \\
\text { Complications }\end{array}$} & \multirow{2}{*}{$\begin{array}{l}\text { Follow-up } \\
\text { Period, mo }\end{array}$} & \multirow{2}{*}{$\begin{array}{l}\text { Stent Technique } \\
\text { Used }\end{array}$} & \multicolumn{2}{|l|}{ NOSE Score ${ }^{a}$} \\
\hline & & & & & & & Preoperative & Postoperative \\
\hline 1 & $3.0 \times 1.4$ & $6 \times 5$ & $\begin{array}{l}\text { Pain at left temple } \\
\text { incision site }\end{array}$ & Yes & 1.20 & $\begin{array}{l}\text { Doyle splints and } \\
\text { silastic sheets }\end{array}$ & 85 & 20 \\
\hline 2 & $1.9 \times 1.2$ & $4.5 \times 7$ & NA & NA & 4.03 & $\begin{array}{l}\text { Doyle splints and } \\
\text { silastic sheets }\end{array}$ & 15 & 0 \\
\hline 3 & $2.2 \times 1.0$ & $5 \times 4$ & $\begin{array}{l}\text { Nasal obstruction } \\
\text { and left scalp seroma }\end{array}$ & No & 4.23 & $\begin{array}{l}\text { Doyle splints and } \\
\text { silastic sheets }\end{array}$ & 85 & 5 \\
\hline 4 & $1.0 \times 0.8$ & $2 \times 2$ & NA & NA & 6.73 & $\begin{array}{l}\text { Doyle splints and } \\
\text { silastic sheets }\end{array}$ & 55 & 25 \\
\hline 5 & $0.8 \times 0.5$ & $2 \times 1$ & NA & NA & 1.60 & Silastic sheets & 40 & 30 \\
\hline 6 & $0.4 \times 0.5$ & $3 \times 2$ & Nasal obstruction & Yes & 8.57 & Silastic sheets & 90 & 20 \\
\hline 7 & $0.2 \times 0.2$ & $1 \times 2$ & NA & NA & 11.63 & Silastic sheets & NA & 5 \\
\hline 8 & $0.7 \times 0.9$ & $4 \times 4$ & NA & NA & 13.93 & Doyle splints & 35 & 0 \\
\hline 9 & $0.4 \times 0.5$ & $3 \times 2$ & NA & NA & 1.83 & Doyle splints & 70 & 20 \\
\hline 10 & $0.7 \times 1.0$ & $4 \times 4$ & $\begin{array}{l}\text { Crusting and nasal } \\
\text { drainage }\end{array}$ & No & 1.70 & Doyle splints & 90 & 50 \\
\hline 11 & $1.5 \times 1.3$ & $6 \times 4$ & NA & NA & 5.80 & Doyle splints & NA & 5 \\
\hline 12 & $0.8 \times 0.7$ & $4 \times 4$ & Crusting & Yes & 12.33 & RBV splints & NA & NA \\
\hline 13 & $\begin{array}{l}2.0 \times 1.5 \text { and } \\
2.0 \times 2.5\end{array}$ & $5 \times 6$ & NA & NA & 3.13 & Doyle splints & NA & 5 \\
\hline 14 & $0.8 \times 1.0$ & $2 \times 2$ & Obstruction & Yes & 9.00 & Doyle splints & NA & 60 \\
\hline 15 & $\begin{array}{l}0.5 \times 0.9 \text { and } \\
0.2 \times 0.3\end{array}$ & $5 \times 6$ & Pain & Yes & 1.80 & Doyle splints & NA & NA \\
\hline 16 & $0.9 \times 0.9$ & $5 \times 6$ & NA & NA & 6.90 & Doyle splints & NA & NA \\
\hline 17 & $0.4 \times 1.0$ & $4 \times 4$ & $\begin{array}{l}\text { Crusting and } \\
\text { obstruction }\end{array}$ & Yes & 8.90 & Doyle splints & NA & NA \\
\hline
\end{tabular}

Abbreviations: NA, not applicable; NOSE, Nasal Obstruction Symptom Evaluation; RBV, Reuter bivalve nasal splint; TPF, temporoparietal fascia.

${ }^{\text {a }}$ Postoperative NOSE scores are from the most recent follow-up visit. 


\section{Discussion}

To our knowledge, this study is the first multi-institutional and third reported retrospective case series of closure of septal perforations using a TPF graft combined with a PDS plate construct. The results are similar to those presented by both Epprecht et $\mathrm{al}^{6}$ and Flavill and Gilmore. ${ }^{11}$ In contrast to the case series by Epprecht et al, ${ }^{6}$ all patients in this cohort underwent a repair using an open septoplasty technique combined with endonasal visualization during closure. In addition, this study is the first, to our knowledge, to evaluate the outcome of symptom resolution validated with preoperative and postoperative NOSE survey evaluation. Although perforation closure is a key objective outcome measurement, resolution of presenting symptoms, in our opinion, represents a clinically meaningful end point because patients with asymptomatic nasal septal perforations do not undergo repair at either institution. Finally, to our knowledge, no prior case series has expanded this technique to include patients with rheumatologic causes, and although only 2 patients in this series had active rheumatologic disease (ie, granulomatosis with polyangiitis), this is the first use of a technique to correct perforations in this subgroup of patients. These patients typically have thin, attenuated septal mucoperichondrial layers, making elevation of mucosal flaps particularly challenging; our technique avoids that problem because the nose remucosalizes the TPF-PDS construct without covering with a mucosal flap.

The limited success rate of closures of septal perforations has led to a wide variety of closure techniques. ${ }^{18}$ Temporoparietal fascia grafts are used in several head and neck procedures ${ }^{13}$ and have long been an established source of grafting material in otologic surgery, ${ }^{19}$ skull base repair, ${ }^{20}$ and ear reconstruction. ${ }^{21}$ The histologic structure of TPF makes it an excellent scaffolding material that likely enhances cellular migration and subsequent remucosalization. ${ }^{15}$ Although no studies, to our knowledge, have evaluated the role of growth factor networks or the architecture of this fascia used for septal perforation repair, numerous studies have demonstrated the benefits of site-specific tissue when designing a scaffold for tissue regeneration, for which TPF serves as an example. ${ }^{22,23}$ Furthermore, it is well known that the growth factor networks of grafting materials, particularly the extracellular matrix, are instrumental in enhancing cellular attachment, migration, and proliferation as well as inducing neovascularization. We suspect that TPF provides this microenvironment that supports remucosalization. ${ }^{24}$ However, further investigation is necessary to prove this theory.

Although harvesting TPF is a straightforward technique, one disadvantage that we have encountered is mediating the balance between adequate tissue for PDS plate coverage and maintaining a thin graft so as to not create further nasal obstruction after the repair. Two patients (patient 3 and patient 10) ultimately had no resolution of their nasal obstruction in addition to crusting. Nasal endoscopic examinations of these patients demonstrated a modest increase in thickness at the site of perforation repair compared with the other patients evaluated, which suggests that excessive graft thickness may have been associated with this outcome. Alternatively, this bulging of the perforation site in these 2 patients may have been due to a technical error of omission by one of us (S.S.) early in the series, or it may be due to a heightened inflammatory reaction in these 2 patients, which may have led to increased thickness of the construct. Mattress suturing of the TPF-PDS construct through and through was initially performed along the periphery only; however, bulging in the central portion through the perforation was noted in the healing phase, and more centralized mattress suturing through the entire construct corrected this problem.

In contradistinction to other reported studies that use a $0.25-\mathrm{mm}$ perforated PDS plate, we use the $0.15-\mathrm{mm}$ PDS plate. Mechanical evaluations of this plate as reinforcement for cartilage grafting has demonstrated adequate elastic moduli. ${ }^{25}$ Not only has this plate provided adequate support in our experience, but it holds the separate advantage of maintaining a thinner profile after repair as well as reducing the volume of the foreign body needed to resorb. In mediating the balance between the adequateness of the graft and the thickness of the graft, it is of critical importance to be meticulous in the harvesting of the TPF graft by only using the true TPF while leaving loose areolar tissue and true temporalis fascia intact.

Although we have not used TPF without the PDS plate, it remains plausible that a similar or improved outcome could be achieved with TPF alone. However, given the thin profile of the PDS plate and its inherent resorptive quality, it is unlikely that removing it from the construct could have prevented the perioperative nasal obstruction noted in several patients. Furthermore, the advantages of the PDS plate (including easier graft manipulation, placement, and securement) are all critical to the success of this technique. In addition, a taut TPF graft (resulting from being sutured around the PDS plate) effectively requires less surface area for remucosalization and prevents outpouching of the TPF into the airway (any laxity of the graft would lead to increased surface area) and therefore results in improved and quicker remucosalization. Finally, its absorbable nature mitigates the long-term risks of exposure and infection. Ultimately, further investigations will be necessary to determine whether or not to use TPF without the PDS plate.

Our experience in the closure of these perforations notably went through a transition. Initially, mucosal coverage on at least a single side of the perforation was attempted. Further experience showed that this coverage was unnecessary, coinciding with the use of a cross-stealing technique of perforation closure ${ }^{26}$ and the experience of Flavill et al. ${ }^{11}$ Although endonasal techniques for septal perforation repair have been reported, ${ }^{6}$ we argue that an open approach is far superior. The open technique allows for enhanced exposure with the improved ability to place and suture the TPF-PDS construct, and it does not truncate the anterior blood supply to 1 septal flap by making a hemitransfixion or Killian incision. It further allows for the simultaneous correction of nasal valve collapse. In our conservative, gradual approach to developing this technique, emphasis was placed on providing more overlap between the graft and the vascularized septal flap, which required larger constructs to be placed through an external approach. Although 
an external incision is created, our experience has not found issues with cosmesis, particularly as this is the same incision performed in our cosmetic rhinoplasty.

In addition, the first 7 patients at Vanderbilt University Medical Center and all the patients at the University of Iowa were treated with only Doyle splints postoperatively. Doyle splints were removed per our institutions' typical external septoplasty or rhinoplasty protocol of removal at approximately 7 days after the procedure. However, the most recent 7 cases at Vanderbilt University Medical Center used silastic sheeting over the perforation closure and only included Doyle splints if concurrent inferior turbinate reduction was performed. The Doyle splints were removed at approximately 7 days, but the silastic sheeting was removed at 5 to 6 weeks after the procedure. We believe that prolonged coverage of the exposed TPF with silastic sheeting for 5 to 6 weeks protects the delicate, ongoing remucosalization and reduces the dependence on patient adherence to a moisturizing nasal regimen. Furthermore, the silastic sheet appears to protect the graft from toxic local conditions, such as active smoking, use of a continuous positive airway pressure device, or nasal sprays.

\section{Limitations}

There remains significant ambiguity in the optimum technique for septal perforation closure. Based on these results, it is clear that this technique holds considerable promise. There are several limitations that should be acknowledged. First, this was a retrospective evaluation with no comparison with separate techniques. Second, although the patient size was consistent with those in other published studies, the small sample size and short follow-up limit the precision of these results. In addition, the mean perforation size was $0.99 \mathrm{~cm}^{2}$, with only 2 patients (patient 1 and patient 13) demonstrating a perforation area larger than $2 \mathrm{~cm}$. Further long-term follow-up and increased patient size are necessary to justify the outcomes ascertained and assess this technique on larger perforations. We also had 2 separate patients with active rheumatologic disease (patient 1 and patient 9) who underwent repair; however, generalizing this technique to all patients in this subgroup should be undertaken with great caution because the systemic nature of these diseases significantly increases the risk of failure.

\section{Conclusions}

Repair of symptomatic nasal septal perforations using a TPF graft combined with a PDS plate that supports mucosal healing is associated with positive outcomes. Septal perforations caused by rheumatologic disease, including granulomatosis with polyangiitis, may also be repaired using this technique. A safe removal time of postoperative silastic sheeting remains variable and uncertain, yet it is likely shorter than the time used for the reported technique. Resolution of symptoms is clinically meaningful in the evaluation of septal perforation repair, and the NOSE survey can serve as objective corroboration to patient-reported postoperative outcomes. Finally, further studies evaluating the cellular biology and histologic characteristics of TPF as a scaffold for nasal mucosal cells and comparison with true temporalis fascia would be beneficial.
Accepted for Publication: December 24, 2018.

Published Online: April 11, 2019.

doi:10.1001/jamafacial.2019.0020

Author Contributions: Drs Morse and Stephan had full access to all the data in the study and take responsibility for the integrity of the data and the accuracy of the data analysis.

Concept and design: Morse, Owen, Stephan.

Acquisition, analysis, or interpretation of data: All authors.

Drafting of the manuscript: Morse, Harris, Owen, Sowder.

Critical revision of the manuscript for important intellectual content: Morse, Owen, Sowder, Stephan.

Statistical analysis: Morse, Owen.

Administrative, technical, or material support:

Morse, Owen, Sowder, Stephan.

Supervision: Morse, Owen, Sowder, Stephan.

Conflict of Interest Disclosures: None reported.

\section{REFERENCES}

1. Friedman M, Ibrahim H, Ramakrishnan V. Inferior turbinate flap for repair of nasal septal perforation. Laryngoscope. 2003;113(8):1425-1428. doi:10.1097/ 00005537-200308000-00031

2. Sarandeses-García A, Sulsenti G, López-Amado M, Martínez-Vidal J. Septal perforations closure utilizing the backwards extraction-reposition technique of the quadrangular cartilage. J Laryngol Otol. 1999;113(8):721-724. doi:10.1017/ S0022215100145025
3. Cho JJW, Taylor RC, Deutschmann MW, Chandarana SP, Marck PA. Polyethylene implants in nasal septal restoration. JAMA Facial Plast Surg. 2013;15(4):275-279. doi:10.1001/jamafacial.2013.840

4. Paloma V, Samper A, Cervera-Paz FJ. Surgical technique for reconstruction of the nasal septum: the pericranial flap. Head Neck. 2000;22(1):90-94. doi:10.1002/(SICI)1097-0347(200001)22:1<90: AID-HED14>3.0.CO;2-2

5. Conrad DJ, Zhang H, Côté DWJ. Acellular human dermal allograft as a graft for nasal septal perforation reconstruction. Plast Reconstr Surg. 2018;141(6):1517-1524. doi:10.1097/PRS. 0000000000004410

6. Epprecht L, Schlegel C, Holzmann D, Soyka M, Kaufmann T. Closure of nasal septal perforations with a polydioxanone plate and temporoparietal fascia in a closed approach. Am J Rhinol Allergy. 2017;31(3):190-195. doi:10.2500/ajra.2017.31.4431

7. Sand JP, Desai SC, Branham GH. Septal perforation repair using polydioxanone plates: a 10-year comparative study. Plast Reconstr Surg. 2015;136(4):700-703. doi:10.1097/PRS. 0000000000001571

8. Pereira C, Santamaría A, Langdon C, López-Chacón M, Hernández-Rodríguez J, Alobid I. Nasoseptal perforation: from etiology to treatment. Curr Allergy Asthma Rep. 2018;18(1):5. doi:10.1007/ s11882-018-0754-1

9. Park JH, Kim Dw, Jin HR. Nasal septal perforation repair using intranasal rotation and advancement flaps. Am J Rhinol Allergy. 2013;27(2): e42-e47. doi:10.2500/ajra.2013.27.3878

10. Goh AY, Hussain SSM. Different surgical treatments for nasal septal perforation and their outcomes. J Laryngol Otol. 2007;121(5):419-426. doi:10.1017/S002221510700566X

11. Flavill E, Gilmore JE. Septal perforation repair without intraoperative mucosal closure. Laryngoscope. 2014;124(5):1112-1117. doi:10.1002/lary. 24386

12. Patel MR, Taylor RJ, Hackman TG, et al. Beyond the nasoseptal flap: outcomes and pearls with secondary flaps in endoscopic endonasal skull base reconstruction. Laryngoscope. 2014;124(4):846-852. doi:10.1002/lary.24319

13. Abt NB, Srikanth P, Puram SV, Deschler DG. Repair of complex pharyngocutaneous fistula using a staged temporoparietal fascial flap. Am J Otolaryngol. 2017;38(2):254-256. doi:10.1016/j. amjoto.2016.11.016

14. Nataliya B, Martin MC. A true single-stage reconstruction of a projected auricle for concha-type microtia incorporating endoscopically harvested temporoparietal fascia. J Craniofac Surg. 2015;26(6):1930-1932. doi:10.1097/SCS. 0000000000001916

15. Tellioğlu AT, Tekdemir I, Erdemli EA, Tüccar E, Ulusoy G. Temporoparietal fascia: an anatomic and histologic reinvestigation with new potential clinical applications. Plast Reconstr Surg. 2000;105(1):4045. doi:10.1097/00006534-200001000-00007 
16. Stewart MG, Witsell DL, Smith $T L$, et al Development and validation of the Nasal Obstruction Symptom Evaluation (NOSE) scale. Otolaryngol Head Neck Surg. 2004;130(2):157-163. doi:10.1016/j.otohns.2003.09.016

17. Rhee JS, Sullivan CD, Frank DO, Kimbell JS, Garcia GJM. A systematic review of patient-reported nasal obstruction scores: defining normative and symptomatic ranges in surgical patients. JAMA Facial Plast Surg. 2014;16(3):219-225. doi:10.1001/jamafacial.2013.2473

18. Døsen LK, Haye R. Surgical closure of nasal septal perforation: early and long term observations. Rhinology. 2011;49(4):486-491. doi: 10.4193/Rhino10.081

19. Karimnejad K, Akhter AS, Walen SG, Mikulec AA. The temporoparietal fascia flap for coverage of cochlear reimplantation following extrusion. Int J
Pediatr Otorhinolaryngol. 2017;94:64-67. doi:10. 1016/j.ijporl.2017.01.020

20. Veyrat M, Verillaud B, Herman P, Bresson D. How I do it: the pedicled temporoparietal fascia flap for skull base reconstruction after endonasal endoscopic approaches. Acta Neurochir (Wien). 2016;158(12):2291-2294. doi:10.1007/s00701-016 2969-z

21. Li D, Xu F, Zhang R, et al. Surgical reconstruction of traumatic partial ear defects based on a novel classification of defect sizes and surrounding skin conditions. Plast Reconstr Surg. 2016;138(2):307e316e. doi:10.1097/PRS.0000000000002408

22. Sellaro TL, Ravindra AK, Stolz DB, Badylak SF. Maintenance of hepatic sinusoidal endothelial cell phenotype in vitro using organ-specific extracellular matrix scaffolds. Tissue Eng. 2007;13(9):2301-2310. doi:10.1089/ten.2006.0437
23. Hoshiba $T, L u H$, Kawazoe $N$ Chen $G$. Decellularized matrices for tissue engineering. Expert Opin Biol Ther. 2010;10(12):1717-1728. doi:10. 1517/14712598.2010.534079

24. Nelson CM, Bissell MJ. Of extracellular matrix, scaffolds, and signaling: tissue architecture regulates development, homeostasis, and cancer. Annu Rev Cell Dev Biol. 2006:22(1):287-309. doi:10. 1146/annurev.cellbio.22.010305.104315

25. Conderman C, Kinzinger M, Manuel C, Protsenko D, Wong BJF. Mechanical analysis of cartilage graft reinforced with PDS plate. Laryngoscope. 2013;123(2):339-343. doi:10.1002/lary 23571

26. Mladina R, Heinzel B. 'Cross-stealing' technique for septal perforation closure. Rhinology. 1995;33 (3):174-176. 